\title{
Fault Tolerant Switched Reluctance Machine for Wind Turbine Blade Pitch Control
}

\author{
Mircea RUBA, Loránd SZABÓ, Florin JURCA \\ Technical University of Cluj, \\ 15, Daicoviciu str., 400020 Cluj, (Romania) \\ tel: (+40)-264-401827, fax: (+40)-264-593117 \\ e-mail: Mircea.Ruba@mae.utcluj.ro
}

\begin{abstract}
The paper's goal is to accomplish a study regarding the usefulness of a fault tolerant machine in wind turbine pitch control. The pitch control both helps to catch the wind at the optimal angle of attack of the blade's airfoil and to turn the blades out of the wind when maximum speed is exceeded. To fulfill this assignment electrical machines are used to control the blade's pitch angle function of wind's speed. The faults that can occur in electrical machines can stop the pitch control system, decreasing drastically the efficiency of the wind turbine. Fault tolerance ability of the pitch controlling machines can avoid such issues. In the paper a fault tolerant switched reluctance machine is studied. As it being simple and cheap it is optimal for such vital applications. Numerical field computations were used to analyze the machine's behavior. An advanced cosimulation was performed by coupling two simulation programs in order to study the machine's drive system and fault tolerance capacity.
\end{abstract}

Index Terms-Fault tolerant, switched reluctance machine, wind turbine, blade control.

\section{INTRODUCTION}

The global market of electrical energy demands for intensive researches in means of developing new energy resources, mainly renewable ones. Clean energy is generate from renewable sources with low environmental impact.

The most frequently used clean energy is produced by specially designed wind turbines that transform wind power in electricity. In our days modern wind turbines are the fastest growing and most cost-effective renewable energy technology in the world. The usage of wind turbine generators is increasing, especially where customers are environmentally conscious. In Europe, the wind turbine market is ever increasing and there are countries that exploit wind power in high proportions, as Spain, Germany, etc.

Wind turbine aerodynamics remains a challenging and crucial research area for wind energy. Clearly, steady-state aerodynamic performance is essential to turbine energy capture, since blade aerodynamic forces produce mechanical energy that is subsequently converted to electrical energy. However, more recent inquiry has focused on adverse time varying aerodynamic loads that wind turbines frequently suffer during routine service.

These undesirable aerodynamic loads impose excessive stresses on turbine blades and gear boxes, and appreciably shorten machine service life.
In the present, the wind energy technical community is contemplating the utility of various aerodynamic control methodologies for mitigating adverse aerodynamic loading [1].

On a pitch controlled wind turbine the turbine's power monitor checks the power output of the turbine several times per second. When the power output becomes too high, it sends an order to the blade pitch mechanism which immediately pitches (turns) the rotor blades slightly out of the wind. Conversely, the blades are turned back into the wind whenever the wind drops again.

The rotor blades thus have to be able to turn around their longitudinal axis (to pitch) controlled by a complex system, as that shown in Fig. 1.

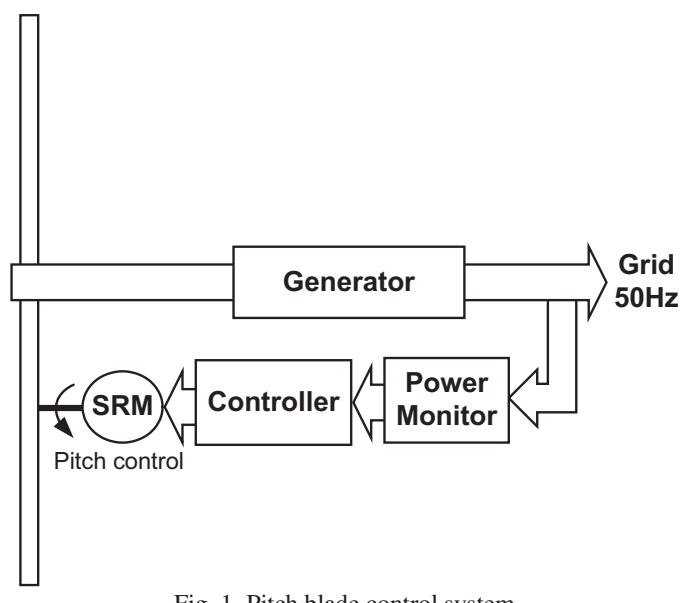

Fig. 1 Pitch blade control system

During normal operation the blades will pitch a fraction of a degree at a time, and the rotor will be turning at the same time.

Designing a pitch controlled wind turbine requires some clever engineering to make sure that the rotor blades pitch exactly the amount required. On a pitch controlled wind turbine, the computer will generally pitch the blades a few degrees every time the wind changes to keep the rotor blades at the optimum angle in order to maximize output for all wind speeds.

This way, the power captured from the wind power can be controlled by a pitch actuator [2].

There are several control schemes that can be applied to investigate the system behaviour in a wind turbine. It is evident from the results that active pitch regulation 
reduces the wind generator output fluctuations. Inverter/converter control can smooth the voltage and power output to make it suitable for the network connection [3].

The development of a high reliability and safe operational system can be achieved using a fault tolerant variant of the switched reluctance motor.

This variant require not only for structure modifications [4], but also for special winding connections and intelligent control devices. To compensate the higher costs demanded by a more complex power converter the use of a relatively simple machine is imposed.

To reach this goal a fault tolerant (FT) switched reluctance motor (SRM) is considered as an optimal solution.

The proposed SRM based drive system was studied by means of simulations. The machine's model was built up using specific software packages. Flux 2D, was used for modelling the machine itself via finite element method (FEM). The MATLAB-Simulink environment was applied for modeling the inverter's control system and to generate the faults for the studied cases.

These two programs were coupled and worked together using the Flux-to-Simulink Technology. This way it was possible to study in details all the typical faulty states of the motor.

\section{THE PURPOSED SRM STRUCTURE}

The development of a fault tolerant variant of an electrical machine implies both topology and phase connection modifications. The structure of the basic fault tolerant SRM is given in [5], with a complex phase system and high number of poles. The torque ripples of this SRM are diminished due to its novel design. The drawbacks of such system are the more complex winding scheme and its power converter.

The fault tolerant SRM in study has a $12 / 14$ pole structure, as shown in Fig. 2.

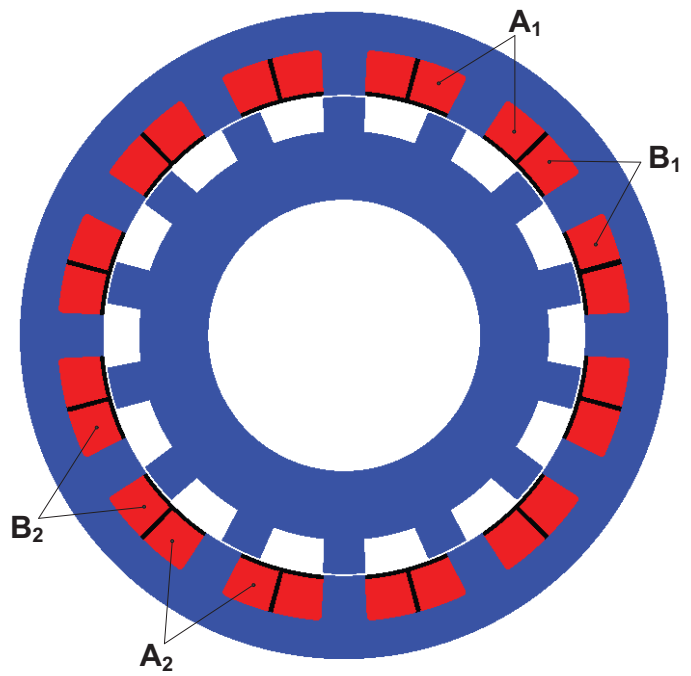

Fig. 2. The purposed fault tolerant SRM
This topology emerges from the classical 12/8 one. The main modifications of the studied machine involve increased rotor pole number and new stator winding connections.

The machine has 12 concentrated stator windings around each pole forming 6 phases. All the windings are split in two parallel connected coils (called channels) as shown in Fig. 2. Hence, each phase (like A, Fig. 2) is divided into two channels (A1 and A2, Fig. 2). Two windings (channels) from opposite poles form a phase.

Practically each phase is doubled. Channels belonging to same phase are fed separately.

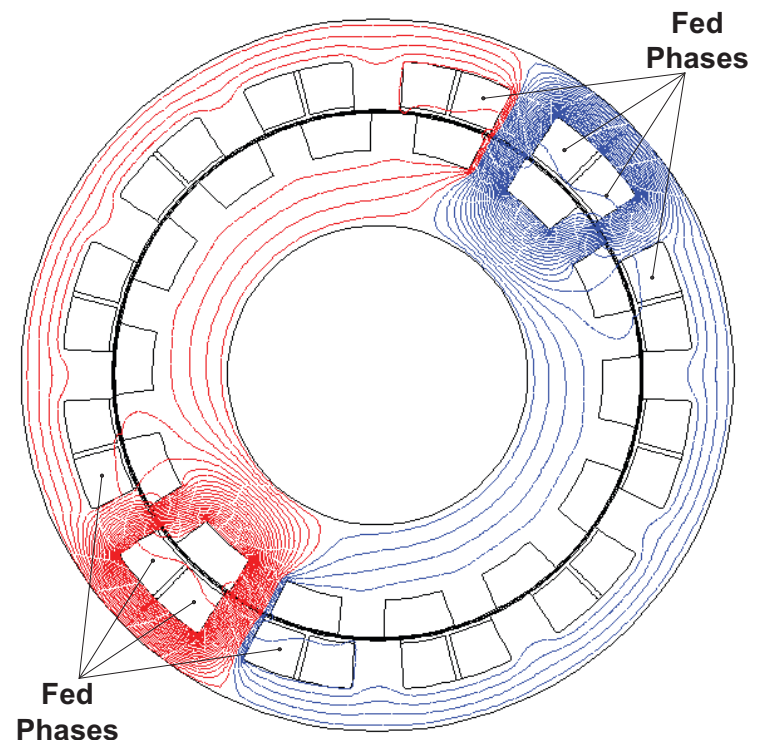

Fig. 3. The flux lines in the fault tolerant SRM

In such rotor design at each moment two adjacent phases are fed (like A and B, Fig. 2), which means in total 4 energized windings (like A1, A2, B1 and B2, Fig. 2). This is called "two phase on" feed technique. Hence at each moment two pairs of adjacent stator poles are contributing to the torque development. This connection helps the motor to overrun the poles with faulty phases and to minimize the torque ripple. By shorting the magnetic flux paths also lower iron losses and higher efficiency can be achieved.

\section{THE POWER CONVERTER TOPOLOGY}

The intelligence of the control system has to fulfill the assignment of isolate, mask and remedy the faults in manner that the machine's behavior to be influenced as less as possible [6], [7]. This will be the main task of the control system.

The purposed converter in study has a separate asymmetrical half bridge connection for each channel, as seen in Fig. 4. 


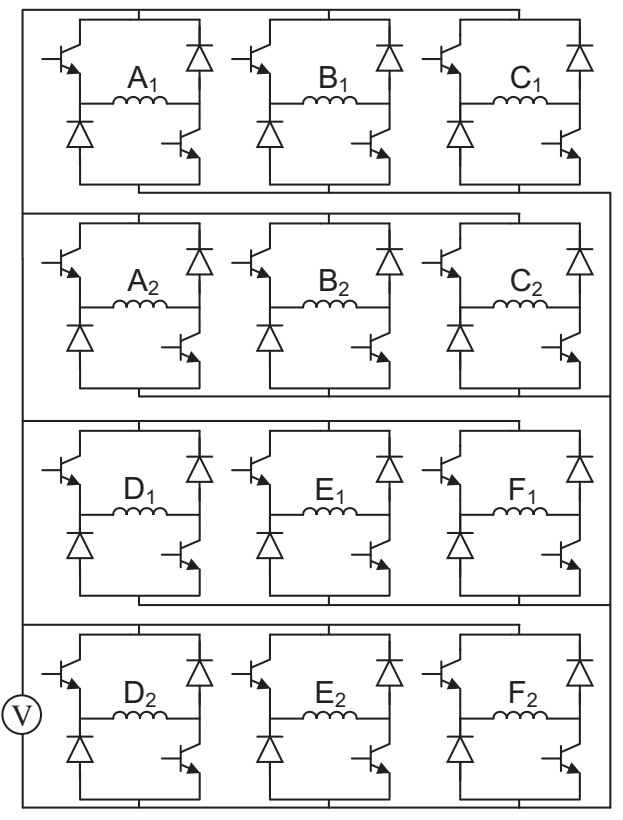

Fig. 4. The FTSRM's power converter

This topology is a quite complex one: 24 solid-state power switches are required. Beside this each branch needs separate control and protection circuit. Nevertheless this sets the independence of the windings in manner to control and feed each channel separately, as the fault tolerant concept demands [8], [9].

\section{The Simulation Model}

The simulations were performed using the co-simulation technique, by coupling two simulation environments to work together.

The model of the SRM and the electric circuits of the power converter were built up in Flux 2D [10].

Simulation of the power converter was possible using an electrical circuit built in Electriflux, Flux's embedded application for circuit design. This was attached to the FEM model of the machine, developed in Flux 2D. The electrical circuit for one channel is given in Fig. 5.

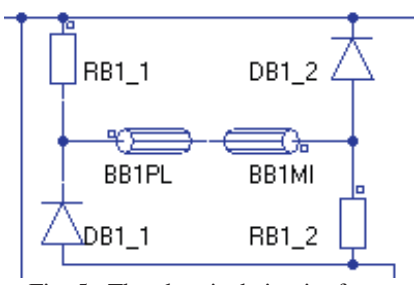

Fig. 5. The electrical circuit of one channel

As compound of two channels, each phase will use two asymmetrical half bridges, built around two coils, each representing the "come and go" sides of the channel's winding (see in Fig. 5).
Usual coils components (like BB1PL and BB1MI) are used to link the two faces of each channel from the geometrical design.

The power switches in the circuit were replaced with resistors. This replacement will allow the modeling of the switches by changing their resistance from a high value, corresponding to OFF state of the switch, to a low value, corresponding to its $\mathrm{ON}$ state. The management of the reverse current is handled by the diodes.

The switching signals are obtained using the coupling between MATLAB/Simulink and Flux 2D [11], [12]. The finite elements model of the SRM practically is embedded in the Simulink program via an S-type function block called "Coupling with Flux2D". All the control signals computed in Simulink are multiplexed and enteres in this block. The main characteristics of the machines computed via Flux 2D (currents in all the phases, torque, speed and position) are returned to the main program through another multiplexed signal line.

The Simulink model is given in Fig. 6.

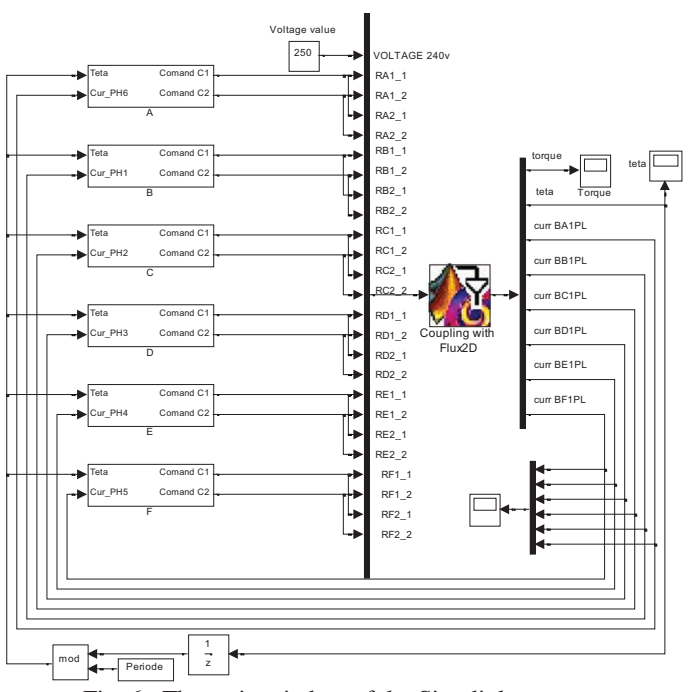

Fig. 6. The main window of the Simulink program

As it can be seen there are six blocks, corresponding to each phase, generating the command signals in accordance with the rotor position and current values from the previous time step.

Six sub-systems (blocks) are simulating the control of the phase currents upon the PWM technique (see Fig. 7).

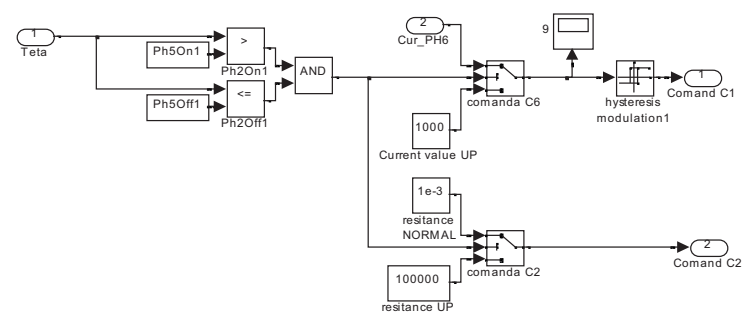

Fig. 7. The phase current controller block 
The commutations of the power switches are set upon the rotor position.

For each time step, there are two main computations. First, the Simulink model sets the command pulses for the switches. These signals are sent to the Flux 2D numeric field model and the computations for the given time step are preceded.

Output values like phase currents, rotor position and torque are sent back to the Simulink model. The computation of the firing angles is set versus the rotor position angle and they are set from an external m-type file together with the maximum current value and the changing switch resistance values.

In order to perform the coupled simulations some parameter adjustments are required. Both programs coupled together require high computer resources. Therefore a compromise needs to be taken by lowering the mesh density in order to obtain affordable computation time but, in meantime, not to decrease the precision of the results.

The open circuit faults will be simulated by imposing OFF state for both switches of one phase/channel. The precision of the PWM is set by the hysteresis band width around the imposed current.

For this study the velocity was imposed to be $600 \mathrm{r} / \mathrm{min}$. The considered regime was no-load steady-state one, so no transient start-up was imposed. The main interest was on the machine's behavior in passing from normal operation to a faulted regime

\section{Simulation Results}

Different cases were studied in order to examine the machine's fault tolerance capability:

- normal operating mode (reference case),

- open circuit of one channel,

- open circuit of one phase,

- open circuit of two channels from different phases,

- open circuit of one phase and one channel from a different phase (worst case in study).

These are considered as being the most common defects that can occur in such system.

The machine's behavior in the above mentioned cases were characterized through the mean torque values.

The simulated machine's geometrical dimensions are:

- stator outer diameter $190 \mathrm{~mm}$

- stator inner diameter $141 \mathrm{~mm}$

- stator pole depth $12 \mathrm{~mm}$

- rotor inner diameter $120 \mathrm{~mm}$

- active stack length $315 \mathrm{~mm}$
The obtained results are given in Fig. 8, where the phase currents and the torque of the SRM are plotted versus time for each case in study.

The normal operation mode is reference for all the rest of the faulty study cases. The mean torque developed in this case is near $20 \mathrm{~N} \cdot \mathrm{m}$ (considered as 100\%). All the mean torques developed by the machine in faulty operation cases will be referred to this value.

\section{A. One channel open circuit failure}

For simulating the open circuit failure the resistance of the power switch was kept constant at a high value corresponding to the OFF state. This way, the machine will behave as having an open circuit winding on one channel.

The current having nil value in Fig. $8 \mathrm{~b}$ corresponds to the faulty channel, as the currents are plotted only for one channel of each phase.

The torque has a small fall corresponding to the missing current pulse. The mean developed torque is close to the reference value (see Table. 1), hence the machine can operate with no significant behavioral changes.

TABLE I

DEVELOPED TORQUE VALUES

\begin{tabular}{|c|c|}
\hline Studied cases & $\begin{array}{c}\text { Mean torques }[\mathrm{N} \cdot \mathrm{m}] \text { and } \\
\text { percentage of the rated torque }\end{array}$ \\
\hline Healthy case & $19.93(100 \%)$ \\
\hline Faulty case 1 & $19.59(98.29 \%)$ \\
\hline Faulty case 2 & $16.16(81.03 \%)$ \\
\hline Faulty case 3 & $19.28(96.71 \%)$ \\
\hline Faulty case 4 & $13.79(69.19 \%)$ \\
\hline
\end{tabular}

B. One phase (two channels) open circuit failure

The fault is modeled in a similar way as in the previous case by setting OFF state of the power switches in all the corresponding electrical circuit branches.

The phase currents in the case of open circuit are given in Fig. 8c.

As the simulation was performed under no-load conditions, at the occurrence of the phase damage, the generated torque felled to nil. In this faulty case the machine is able to develop more than $80 \%$ of the reference rated torque.

Naturally, the torque ripples are greater than in the previous case, becoming a compromise to fulfill the continuous operation assignment. 

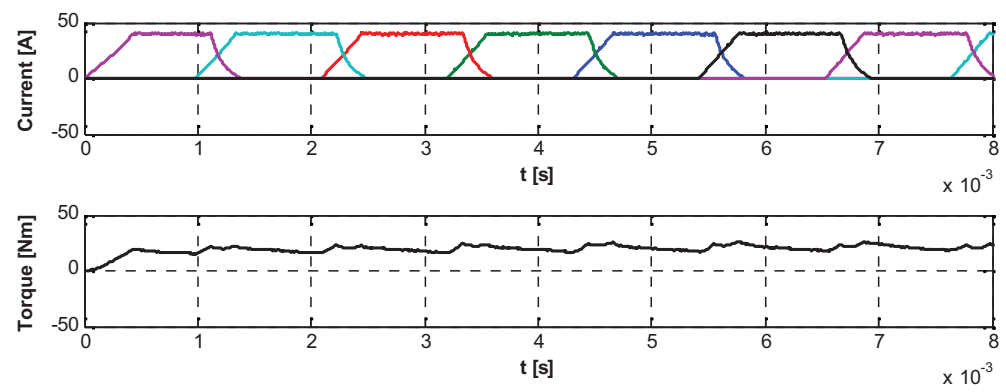

a) normal study case
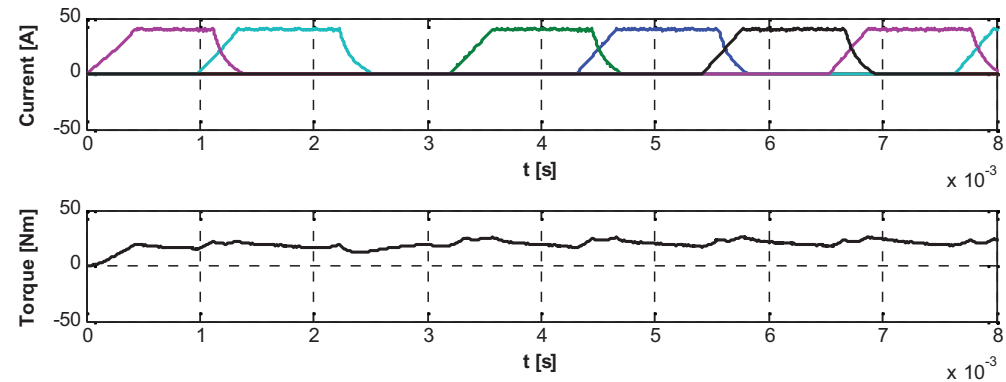

b) one channel open circuit
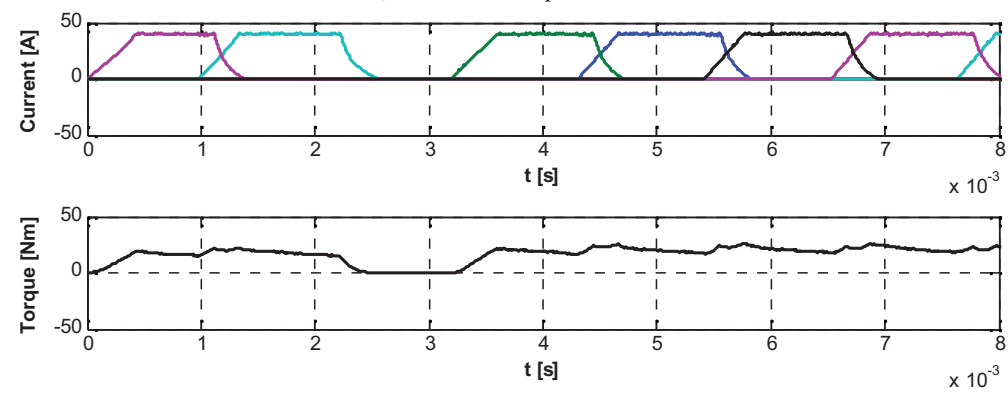

c) one phase open circuit
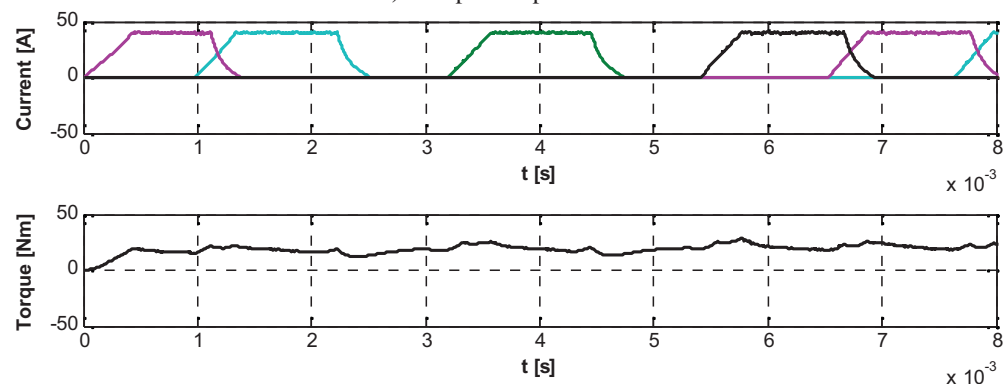

d) two channel open circuit

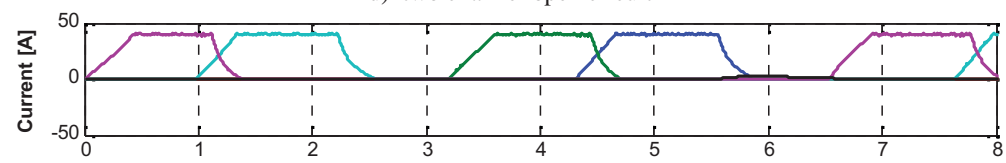

$\mathrm{t}[\mathrm{s}]$

$\times 10^{-3}$

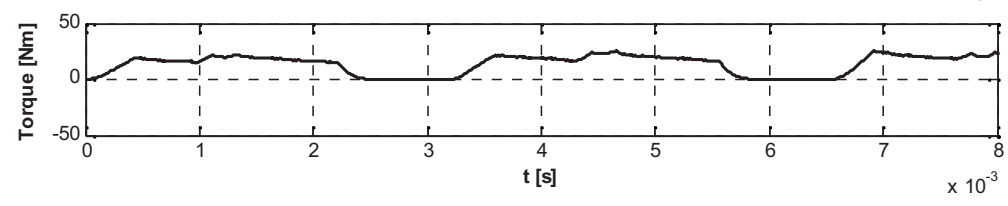

e) one phase and one channel open circuit

Fig. 8. The current and torque characteristics 


\section{Two channels from two phases open circuit failure}

In the situation of the faults on two different channels from two different phases (Fig. 8d) the torque ripples are higher than the case of one channel open circuit. But the machine's mean torque seems not to be influenced by these faults, as Table 1 show that more then $96 \%$ of the rated torque is developed in this case. Due to the phase to channel division, the machine can operate continuously and can develop significant torque, even in the case of this double failure condition.

\section{One phase and one channel open circuit failure}

The worst case in study is the fault of an entire phase, and a second fault on one channel from different phase.

The torque characteristic falls to nil, because of the no load and no inertia conditions of the simulqation program's mechanical settings (see Fig. 8e).

The torque ripples are the most significant in this case as compared to the previous ones. In spite of the severity of the fault the machine is able to develop nearly $70 \%$ of its rated torque.

\section{CONCLUSIONS}

The coupled simulation program connecting two software environments (FLUX 2D and Simulink) was useful in studying the effects of different winding faults on the torque developing capacity of the fault tolerant SRM in study. Thus the computing power of FLUX 2D joined the advanced facilities of MATLAB / Simulink in simply describing the different working regimes of the machines and drives taken into study.

Problems were regarding the computation times. In order to obtain precise results in reasonable time the quality of the FEM model's mesh had to be optimized.

It was demonstrated by means of simulations that increasing the number of rotor poles, separating the phases/channels, setting new connections between the existing windings and using a complex control system all provide good solutions for the fault tolerant SRM based electrical drive system.

It was also proved that the proposed $12 / 14$ poles SRM has considerable fault tolerant capacity. This increased fault tolerance unfortunately is achieved by more complex constructions (especially that of the power converter).

An improvement of the performances of the SRM under faults will be studied in the future. After detecting the fault in a winding it has to be isolated and the current in the remaining healthy phases has to be increased. By this the average torque can be held at its rated value, but of course the torque ripples will be increased.
This solution can be used only if the windings and the cooling system of the machine were designed to support the greater currents.

\section{REFERENCES}

[1] Schreck, S., Robinson, M., Wind Turbine Blade Flow Fields and Prospects for Active Aerodynamic Control, ASME 2007 Fluids Engineering Division, San Diego, California, July 30-August 2, 2007.

[2] Mulajdi, E., Butterfield, C.P., Pitch controlled variablespeed wind turbine generation, IEEE Transactions on Industry Applications, vol. 37, no. 1 (Jan/Feb 2001), pp. $240-246$

[3] Sharma, H., Pryor, T., Islam, S., Effect of pitch control and power conditioning on power quality of variable speed wind turbine generators, Proceedings of the Australasian Universities Power Engineering Conference (AUPEC '2001), 2001, pp. 95-100.

[4] Ruba, M., Szabó, L., Strete Larisa, Viorel, I.A., Study on Fault Tolerant Switched Reluctance Machines, Proceedings of the $18^{\text {th }}$ International Conference on Electrical Machines (ICEM '2008), Vilamoura (Portugal), on CD: Fullpaper_comm_id01200.pdf.

[5] Ruba, M., Anders, M., Fault Tolerant Switched Reluctance Machine Study, Proceedings of the International Conference on Power Electronics, Intelligent Motion and Power Quality (PCIM '2008), Nürnberg (Germany), 2008, on CD: S2d-3.pdf

[6] Mir, S., Islam, M.S., Sebastian, T., Husain, I., Fault tolerant switched reluctance motor drive using adaptive fuzzy logic controller, Proceedings. of the IEEE International Electric Machines and Drives Conference (IEMD '03), Madison (WI, USA); vol. 2, pp. 835-841.

[7] Park, B.-G., Kim, T.-S., Ryu, J.-S., Hyun, D.-S., Fault Tolerant Strategies for BLDC Motor Drives under Switch Faults, Record of the 2006 IEEE Industry Applications Conference, Tampa (FL, USA), vol. 4, pp. 1637-1641.

[8] Szabó, L., Ruba, M., Fodorean, D., Study on a Simplified Converter Topology for Fault Tolerant Motor Drives, in Proc. of the $11^{\text {th }}$ Intern. Conf. on Optimization of Electrical and Electronic Equipment (OPTIM '2008), Braşov (Romania), pp. 197-202, 2008.

[8] Kasson, M., Eaves, S., Fault tolerant motor drive arrangement with independent phase connections and monitor system, Patent no. WO01/91265, 29 November 2001.

[9] Briso-Montiano, J.R., Karrelmeyer, R., Dilger, E., Simulation of Faults by Means of Finite Element Analysis in a Switched Reluctance Motor, in Proc. of the COMSOL Multiphysics User's Conference, Frankfurt (Germany), pp. 225-231, 2005.

[10] Busi, M., Cadeau-Belliard, S., Induction Motor Drive using FLUX to SIMULINK Technology, FLUX Magazine, no. 47, pp. 15-17, January 2005.

[11] du Peloux, B., Lacombe, G., Engineering-focused software for the design of the drive of electrical machines, in Proc. of the 18th Intern. Conf. on Electrical Machines (ICEM '2008), Vilamoura (Portugal), pp. 1-4. 